\title{
Multiscale composition modulated Ti-Al composite processed by severe plastic deformation
}

\author{
X. Sauvage ${ }^{1}$, E. W. Lui ${ }^{2}$, K. Xia ${ }^{2 *}$ \\ 1- University of Rouen, CNRS UMR 6634, Groupe de Physique des Matériaux, Faculté des \\ Sciences, BP12, 76801 Saint-Etienne du Rouvray, France
}

2- ARC Centre of Excellence for Design in Light Metals, Department of Mechanical Engineering, University of Melbourne, Victoria 3010, Australia

*Corresponding author :

Xavier Sauvage

xavier.sauvage@univ-rouen.fr

Tel.: + 33232955142

Keywords: SPD; co-deformation; Titanium; Aluminum; UFG structure

\begin{abstract}
Using severe plastic deformation processes to consolidate and co-deform powder mixtures to make ultrafine grain composites is a very attractive approach because it offers an almost nonlimited room for combinations of phases and composite structures. The aim of this work was to investigate the mechanisms operating at different length scales and leading to multiscale structures, namely co-deformation, fragmentation and mechanical mixing. A Ti-Al composite was processed from a Ti-Al powder mixture prepared by ball milling and subsequently deformed by equal channel angular pressing. Microstructures were characterized at all length scales, down to the nanometre, using optical microscopy, scanning electron microscopy and transmission electron microscopy. It was found that the final structure exhibits unique features at various length scales. Chemical heterogeneities at the micron scale are the result of codeformation, while at the submicron scale they result from the fragmentation and necking of the Ti hard phase. Then, at the nanometer scale, intermixing occurred and nanoscaled intermetallic particles were discovered. This work highlights the possibilities offered by all these mechanisms to design ultrafine grain composite structures for optimized properties.
\end{abstract}




\section{1- Introduction}

Extensive research has been carried out during the past 20 years on Ultra Fine Grained (UFG) metals and alloys because they offer a huge potential for applications where a high strength is needed. Indeed, following the Hall-Petch law [1, 2], decreasing the grain size of metallic alloys looks like an extremely promising strategy to increase the yield stress when the onset of plasticity is controlled by dislocation motion. There are, however, a few important issues and limitations, namely material processing, thermal stability and lack of ductility. Different routes have been tried and explored for the processing and they fall in two categories. The first is a bottom-up approach like powder consolidation by Spark Plasma Sintering (SPS) [3] or electrodeposition [4]. The second is a top-down approach like refinement by Severe Plastic Deformation (SPD) [5, 6]. Research in this latter field has been very active during the past 10 years because SPD techniques provide often bulk materials free of any porosity. Beside, it has been shown that optimized processing routes (including eventually the initial state and postdeformation thermal treatments) could give rise to unique structures with so-called "nonequilibrium" Grain Boundaries (GB) [7], or combinations of UFG structure and nano-scaled

precipitates [8], or bi-modal structures [9], or GB segregations [10]. All these specific features provide some additional opportunities for tuning and optimizing the mechanical or multifunctional properties of UFG alloys processed by SPD.

Among all these new materials, multiphase alloys are of high interest. It is known for a long time that the combination of a hard phase and a soft one at the nanoscale could be a very successful strategy to achieve high strength with significant toughness [11]. This is also the well known case of drawn pearlitic steels [12] or copper based nanocomposites wires [13] where a ultra-high strength is achieved in combination with a good level of ductility. Various attempts have been made to achieve similar UFG structure using SPD processes like High Pressure Torsion (HPT), Accumulative Roll Bonding (ARB) or Equal Channel Angular Pressing (ECAP) in the $\mathrm{Cu}-\mathrm{Cr}$ [14], $\mathrm{Cu}-\mathrm{W}$ [15], $\mathrm{Cu}-\mathrm{Ag}$ [16], $\mathrm{Cu}-\mathrm{Al}$ [17] and $\mathrm{Cu}-\mathrm{Fe}$ [18] systems. It is very interesting to note that the grain sizes achieved in such systems were often much smaller than in the corresponding pure metals, leading to exceptional strength. This feature can be attributed to the slow motion of hetero-phase interfaces and the resulting limited dynamic recovery. However, in all these examples, the starting material is a bulk alloy containing two phases. Thus, the flexibility and the possibilities are intrinsically limited by the thermodynamics of phase equilibrium. Therefore, it has been proposed to use SPD to consolidate and co-deform multiphase composites [19-21]. This new route, combining the bottom-up and the top-down approach, is very attractive because it offers an almost non- 
limited room for combinations of phases and thus for UFG composite structures. For example, it has been proposed to improve the ductility of UFG materials processed by SPD by incorporating a small volume fraction of a ductile phase [21]. Beside, it has also been proposed to control the initial particle size distribution in order to elaborate a multiscale structure that could also offer an interesting combination of strength and ductility. Now, the challenge is fascinating and clear: how is it possible to control the final multiscale and multiphase structure? It is obviously necessary to identify the underlying mechanisms of co-deformation, grain fragmentation and refinement in multi-phase and multi-scale systems where some very soft and ductile phases could be associated with rather hard and brittle phases. As already reported in the literature (see [22] for a review), in the early stage of the SPD process, the deformation is mainly localized in the softer phase that flows around the harder one. However, after some time, progressively the harder phase is fragmented and finally a rather homogeneous nanoscaled structure can be achieved. But hetero-phase interfaces may be strongly affected by the plastic deformation and some mechanical mixing has often been reported $[13,14,18,23]$, leading sometime to a full decomposition of the second phase.

For a better understanding of all these mechanisms operating at different length scales, we have investigated a $\mathrm{Ti}-\mathrm{Al}$ composite prepared from $\mathrm{Ti}$ and $\mathrm{Al}$ powders and consolidated by SPD using ECAP. Earlier studies have shown indeed that an interesting combination of strength and ductility could be achieved in this system as a result of a multi-scale structure [21].

\section{2- Experimental}

Powders of titanium (-325 mesh, 99.5\% purity) and aluminium (-200 mesh, 99.7\% purity) were mixed to make a composition of $\mathrm{Ti}-47$ at.\% Al. The grain sizes in the original $\mathrm{Ti}$ and $\mathrm{Al}$ powders were -9 and $-6 \mu \mathrm{m}$, respectively. Ball milling (BM) was carried out under vacuum using a high-energy planetary mill with stainless steel balls (10 mm diameter) for $40 \mathrm{~h}$ at 300 $\mathrm{rpm}$. The ball to powder ratio was 10:1 and $1 \mathrm{wt}$.\% stearic acid was added as the process controlling agent. The mixed powder after BM was consolidated by ECAP using a $90^{\circ}$ die with channel cross sections of $9 \times 9 \mathrm{~mm}$. ECAP was conducted at $350{ }^{\circ} \mathrm{C}$ with a pressing speed of $20 \mathrm{~mm} \mathrm{~min}^{-1}$ for up to 12 passes following route C. A back pressure of $200 \mathrm{MPa}$ was applied to ensure shearing of the particles and thus full consolidation [20]. 
Samples for optical microscopy (OM) and scanning electron microscopy (SEM) analysis were mechanically ground from 150 to 4000 grade silicon carbide sandpapers under running water. The ground samples were then polished through chemical-mechanical treatment using colloidal silica $\left(\mathrm{SiO}_{2}\right)$ based oxide polishing suspensions on a rotating polishing pad. The metallographic surface was cleaned in an ultrasonic bath with acetone and dried with compressed air. Observation of microstructure was performed using an Olympus OM and a FEI Quanta 200F SEM with an accelerating voltage of $15 \mathrm{kV}$ and a Back Scattered Electron (BSE) detector.

Transmission Electron Microscopy (TEM) samples were prepared by ion milling using a Gatan PIPS (incidence angle $\mathfrak{B}^{\circ}$, energy $3 \mathrm{kV}$ ) in the cross section of the ECAP billet. Then, samples were investigated in a JEOL-ARM200F electron microscope operating at 200kV. Scanning TEM (STEM) imaging and mapping were performed with a probe size of $0.2 \mathrm{~nm}$ and a convergence angle of 34 mrad. High-Angle Annular Dark Field (HAADF) images providing Z-contrast were recorded with collection angles in the range of 50 to $180 \mathrm{mrad}$. Elemental mapping was performed using energy-dispersive X-ray spectroscopy (EDS) with a JEOL JED2300 detector.

\section{3- Results}

The initial ball milling operation (used to mix up the original $\mathrm{Ti}$ and $\mathrm{Al}$ powders), leads to the fragmentation and the agglomeration of both phases [21]. Beside, X-ray diffraction analysis has shown that no significant reaction occurred during this process conducted at room temperature, and no intermetallic phases were detected [21]. After ECAP consolidation, the material is fully compacted with a density larger than $99.9 \%$ of the theoretical density. A low magnification image obtained by optical microscopy is displayed on Fig.1(a) where the bright zones are $\mathrm{Al}$ rich and dark zones are Ti rich. Obviously there is some chemical heterogeneity with a length scale of 10 to $30 \mu \mathrm{m}$. SEM was used to confirm this point (Fig. 1(b)). One should note however that the atomic number of $\mathrm{Al}$ being lower than that of $\mathrm{Ti}$, the contrast is reversed on the BSE image and $\mathrm{Al}$ rich zones or phases appear now dark. Three intensity levels are clearly observed on this image: black for $\mathrm{Al}$, white for $\mathrm{Ti}$ and the intermediate grey level correspond to areas where $\mathrm{Al}$ and $\mathrm{Ti}$ are mixed up at a finer scale that cannot be resolved on the image. Thus, another length scale of composition fluctuations is revealed, both inside $\mathrm{Al}$ and Ti rich particles, with a length scale not larger than a few micrometers. 
Using STEM-HAADF providing Z-contrast, it was possible to further explore the complex microstructure generated by ECAP consolidation. A typical image is provided in Fig.2(a) where $\mathrm{Al}$ rich zones are darkly imaged and are about 0.5 to $1 \mu \mathrm{m}$ in size. There are as well some grey zones that could be attributed to a fine scale mixture of $\mathrm{Ti}$ and $\mathrm{Al}$.

To confirm this point, EDS mapping and measurements were carried out (Fig.2(b)). Three kinds of constituents were found in this complex fine scale structure: (i) titanium with an extremely low amount of Al (location 1) that could be attributed to the hcp Ti phase; (ii) an almost equi-atomic mixture of $\mathrm{Al}$ and $\mathrm{Ti}$ (location 2) corresponding most probably to the intermetallic ordered $\mathrm{L1}_{0}$ rphase TiAl [24]; (iii) titanium with a significant amount of $\mathrm{Al}$ in solid solution (location 3), but within the solubility limit given by the equilibrium phase diagram at $350^{\circ} \mathrm{C}$ (ECAP processing temperature) [25].

The fragmented and interconnected structure was further analyzed at a finer scale. Fig.3 shows a Ti rich grain embedded in an $\mathrm{Al}$ rich matrix. The intermetallic $\gamma$ phase TiAl was again detected (location 2) with a small deviation to the stoichiometry but still fitting the equilibrium solubility limit [25]. The amount of $\mathrm{Al}$ in solid solution in $\mathrm{Ti}$ (location 1 ) is very low (below 1 at.\%); however surprisingly, the amount of Ti detected in solid solution in the $\mathrm{Al}$ rich phase (location 3) is rather high (about 12.5at.\%). From the equilibrium phase diagram, it does not correspond to any identified intermetallic phase in this system and it is much higher than the equilibrium solubility limit (well below 1 at.\% $\mathrm{Ti}$ in fcc $\mathrm{Al}$ at $350^{\circ} \mathrm{C}[25]$ ). Thus, it could be either a super saturated solid solution resulting from the SPD process as already reported in other systems $[13,14,18,23]$ or a fine mixture of pure fcc Al with nanoscaled Ti rich phases. Indeed, as shown in Fig.4, some regions of the material consolidated by ECAP exhibit a nanoscaled structure with a mean grain size as small as 50 $\mathrm{nm}$. In such regions, numerous phases were identified using electron diffraction (like the typical SAED pattern set in Fig. 4(a)), namely the fcc Al, the hcp Ti, the $\gamma$ phase TiAl and the intermetallic phases $\mathrm{Al}_{2} \mathrm{Ti}$ and $\mathrm{Al}_{3} \mathrm{Ti}$. It is not surprising to detect this latter phase since it is often reported as the early stage of the reaction of $\mathrm{Ti}$ and $\mathrm{Al}$ before the formation of the equilibrium $\gamma \mathrm{TiAl}[26,27]$. The $\mathrm{Al}_{2} \mathrm{Ti}$ phase was rather unexpected, but as already reported in a similar material processed in a different way, it could be the result of local composition modulations [28]. However, even if such multiphase and nanoscaled regions we observed quite often in our samples, only STEM-HAADF and EDS analyses could prove without any ambiguity the presence of the $\mathrm{Al}_{2} \mathrm{Ti}$ phase because of the large number of possible lattice reflections from the various phases in the Al-Ti system. On the STEM-HAADF image 
(Fig.5(a)) some nanoscaled bright particles, i.e. enriched in Ti, clearly appear. They were also imaged and analyzed by EDS (Fig. 5(b)). A stoichiometry very close to the $\mathrm{Al}_{2} \mathrm{Ti}$ phase was detected in various locations (locations labelled 1). The slight deviation from the exact stoichiometry could be due to the very small grain size and a possible overlap of the particle and the surrounding $\mathrm{Al}$ rich matrix within the TEM foil thickness. In other regions (data not shown here), some nanoscaled regions with the Al-Ti stoichiometry were also detected. However, it is interesting to note that at such small length scale of only 10 to $50 \mathrm{~nm}$, it seems that some super saturated solid solution of Ti in Al could be found (locations labelled 2 in Fig. 5 where the Ti concentration exceeds very significantly the equilibrium solubility). Again, it could be either a super saturated solid solution resulting from the SPD process as already reported in other systems $[13,14,18,23]$ or a fine mixture of pure fcc Al with nanoscaled Ti rich phases that could not be seen on the STEM image. In any case, there is obviously some chemical heterogeneity down to the nanometer scale in the composite after the ECAP consolidation.

\section{Discussion}

Earlier work has shown that the combination of ball milling and consolidation by ECAP of Al-Ti powder mixtures could give rise to a multiscale structure with high strength and plasticity [21]. In the present manuscript, we have detailed our new experimental data collected to provide a thorough view from the micrometer down to the nanometer scale of the complex structure achieved by such a process. First, it clearly appears that there are modulations of the composition at different scales. Second, even if the process was conducted at relatively low temperature where atomic mobility is rather limited in bulk materials, part of the aluminium has reacted with the surrounding titanium to form some ordered intermetallic particles.

The initial material is a mixture of $\mathrm{Al}$ and Ti particles with a micrometer size and thus exhibits composition modulations at this length scale, i.e. about 5-10 $\mathrm{m}$. These two original phases exhibit quite different flow stresses but during the process, both phases co-deform, as imaged on the optical microscopy in Fig. 1(a). This co-deformation that starts during the ball milling operation and continues during the ECAP consolidation, creates an interconnected structure and is essential for the densification and compaction of the mixture. But most importantly, it creates the first level of composition modulation as schematically represented in Fig. 6(a). It is clear that a significant increase in the total applied strain during the SPD process would reduce the length scale of these modulations, but another mechanism operates. 
Indeed, even if the plastic deformation is mainly supported by the softer phase (aluminium), local instabilities lead to the necking and progressive fragmentation of the harder phase (titanium). This phenomenon can be clearly observed in Fig. 1 (b) and it is interesting to note that very similar features have been reported in various multiphase systems processed by SPD $[14,15,22,23]$. This mechanism leads to the formation of fine scale Ti particles inside the Aluminium as observed by TEM (Fig.2 and 3). As schematically described on Fig. 6(b), it creates an additional length scale of composition modulations in a range of $100 \mathrm{~nm}$ to $1 \mu \mathrm{m}$. Larger amount of deformation would eventually further reduce this length scale, but as shown by our EDS analyses (Fig. 2(b) and 3(b)), Al and Ti obviously mix-up and react during the process. Ball milling was performed at room temperature, while ECAP was done at a temperature of only $350^{\circ} \mathrm{C}$. At this temperature, even nanoscaled Ti-Al multilayers are stable and do not transform into the more stable $\gamma \mathrm{TiAl} \mathrm{L1} 1_{0}$ ordered intermetallic phase [26]. Thus, in the present case, the atomic mobility would be significantly enhanced because of the large density of defects created during the severe plastic deformation. Our EDS analyses seem to confirm this point, since some $\mathrm{Al}$ in solid solution was found in titanium (Fig. 2(b) location 2) and also a super saturated solid solution of Ti in aluminium was detected (Fig. 3(b) location 3). It is interesting to note that such deformation induced super saturated solid solution have already been reported in other systems processed by SPD [14, 18, 23]. In the present case, such an accelerated diffusion and deformation induced mechanical mixing may promote the nucleation and growth of intermetallic phases, leading to another length scale of composition modulations, down to a range of 10 to $50 \mathrm{~nm}$, as revealed by TEM (Fig.4 and Fig.5). This third level of composition modulations is represented schematically in Fig. 6(c). At this level, the local composition is of course directly correlated to the intermetallic phase that nucleates $\left(\mathrm{Al}_{3} \mathrm{Ti}, \mathrm{Al}_{2} \mathrm{Ti}, \mathrm{TiAl}, \mathrm{Ti}_{3} \mathrm{Al}\right)$. As reported in the literature [26, 27], the final reaction product between $\mathrm{Al}$ and $\mathrm{Ti}$ should be the most stable $\mathrm{TiAl}$ phase, but it could be often preceded by the aluminium rich $\mathrm{Al}_{3} \mathrm{Ti}$. In the present material, the local concentration gradients driven by the SPD may however give rise to the favourable nucleation of other phases like $\mathrm{Al}_{2} \mathrm{Ti}$ and $\mathrm{Ti}_{3} \mathrm{Al}$. Finally, three level composition modulations with different length scales were created during the SPD process. These length scales are controlled by different mechanisms, namely codeformation, fragmentation and mechanical mixing. Thus SPD of powder mixtures open a new field for the creation of unique structures to achieve multifunctional or enhanced mechanical properties (combination of high strength and ductility for example). However, the different length scales and associated mechanisms described above depend on various 
parameters. Further investigations would be necessary on such two-phase structures to understand the influence of the volume fraction, the flow stress difference, the initial particle size, the level of deformation, the deformation pass, the hydrostatic pressure, the strain rate, and the processing temperature.

\section{Conclusions}

(i) A Ti-Al powder mixture prepared by ball milling was successfully consolidated by ECAP to achieve a fully dense composite material.

(ii) The composite exhibits composition fluctuations at various length scales from the micrometer down to the nanometer.

(iii) Composition fluctuations revealed at the micrometer scale are controlled by the codeformation process.

(iv) Composition fluctuations revealed at the sub-micron level are obviously the result of the local necking and subsequent fragmentation of the hard Ti particles.

(v) Nanometer scale composition fluctuations are triggered by atomic scale mixing operating during the deformation and leading to the nucleation and growth of diverse intermetallic phases.

(vi) Thus, the final ultrafine composite structure is a multiscale composition modulated Ti-Al composite. It demonstrates all the possibilities offered by SPD processing of powder mixtures for the design of fine scale composites for optimized properties.

\section{References}

\begin{tabular}{|l|l|}
\hline$[1]$ & $\begin{array}{l}\text { Hall EO (1951) The Deformation and Ageing of Mild Steel: III Discussion of } \\
\text { Results.Proc. Phys. Soc. B 64:747-753. }\end{array}$ \\
\hline$[2]$ & Petch NJ (1953) The cleavage strength of polycrystals. J. Iron Steel Instrum. 173:25. \\
\hline$[3]$ & $\begin{array}{l}\text { Orrù R, Licheri R, Locci AM, Cincotti A, Cao G (2009) Consolidation/synthesis of } \\
\text { Materials by electric current activated/assisted sintering. Mat. Sci. Eng. R63:127-287. }\end{array}$ \\
\hline$[4]$ & $\begin{array}{l}\text { Lei Lu, Yongfeng Shen, Xianhua Chen, Lihua Qian, Lu K (2004) Ultrahigh Strength } \\
\text { and High Electrical Conductivity in Copper. Science 304 :422-426. }\end{array}$ \\
\hline$[5]$ & $\begin{array}{l}\text { Valiev RZ, Estrin Y, Horita Z, Langdon TG, Zehetbauer MJ, Zhu YT (2006) Producing } \\
\text { bulk ultrafine-grained materials by severe plastic deformation J.O.M. vol. 58, issue } \\
4: 33-39 .\end{array}$ \\
\hline
\end{tabular}




\begin{tabular}{|c|c|}
\hline [6] & $\begin{array}{l}\text { Valiev RZ, Islamgaliev RK, Alexandrov IV (2000) Bulk Nanostructured Materials } \\
\text { from Severe Plastic Deformation Prog. Mater. Sci. 45:103-189. }\end{array}$ \\
\hline [7] & $\begin{array}{l}\text { Sauvage X, Wilde G, Divinsky S, Horita Z, Valiev RZ (2012) Grain boundaries in } \\
\text { ultrafine grained materials processed by severe plastic deformation and related } \\
\text { phenomena. Mat. Sci. Eng. A 540:1-12. }\end{array}$ \\
\hline [8] & $\begin{array}{l}\text { Zhao YH, Liao XZ, Jin Z, Valiev RZ, Zhu YT (2004) Microstructures and mechanical } \\
\text { properties of ultrafine grained } 7075 \text { Al alloy processed by ECAP and their evolutions } \\
\text { during annealing. Acta Mater 34752:4589-4599. }\end{array}$ \\
\hline [9] & $\begin{array}{l}\text { Kaveh Edalati, Shoichi Toh, Hideaki Iwaoka, Masashi Watanabe, Zenji Horita, } \\
\text { Daisuke Kashioka, Kyosuke Kishida, Haruyuki Inui (2012) Ultrahigh strength and high } \\
\text { plasticity in TiAl intermetallics with bimodal grain structure and nanotwins. Scripta } \\
\text { Materialia 67:814-817. }\end{array}$ \\
\hline$[10]$ & $\begin{array}{l}\text { Sauvage X, Ganeev A, Ivanisenko Y, Enikeev N, Murashkin M, Valiev R (2012) Grain } \\
\text { boundary segregation in UFG alloys processed by severe plastic deformation. Adv. } \\
\text { Eng. Mat. 14:968-974. }\end{array}$ \\
\hline$[11]$ & $\begin{array}{l}\text { Sigl LS, Mataga PA, Dalgleish BJ, McMeeking RM, Evans AG (1988) On the } \\
\text { toughening of brittle materials reinforced with a ductile phase. Acta Metall. 36:945- } \\
\text { 953. }\end{array}$ \\
\hline$[12]$ & $\begin{array}{l}\text { Embury JD, Fisher RM (1966) The structure and properties of drawn pearlite. Acta } \\
\text { Metallurgica 14:147-159. }\end{array}$ \\
\hline [13] & $\begin{array}{l}\text { Dierk Raabe, Pyuck Choi, Yujiao Li, Alexander Kostka, Xavier Sauvage, Florence } \\
\text { Lecouturier, Kazuhiro Hono, Rainer Kirchheim, Reinhard Pippan, David Embury } \\
\text { (2010) Metallic composites processed via extreme deformation: Towards the limits of } \\
\text { strength in bulk materials. MRS Bulletin 35:982-991. }\end{array}$ \\
\hline [14] & $\begin{array}{l}\text { Sauvage X, Jessner P, Vurpillot F, Pippan R (2008) Nanostructure and properties of a } \\
\text { Cu-Cr composite processed by severe plastic deformation. Scripta Mater 58:1125-1128. }\end{array}$ \\
\hline$[15]$ & $\begin{array}{l}\text { Sabirov I, Pippan R (2005) Formation of a W-25\%Cu nanocomposite during high } \\
\text { pressure torsion. Scripta Mater. 52:1293-1298. }\end{array}$ \\
\hline$[16]$ & $\begin{array}{l}\text { Tian YZ, Wu SD, Zhang ZF, Figueiredo RB, Gao N, Langdon TG (2011) } \\
\text { Microstructural evolution and mechanical properties of a two-phase } \mathrm{Cu}-\mathrm{Ag} \text { alloy } \\
\text { processed by high-pressure torsion to ultrahigh strains. Acta Materialia 59:2783-2796. }\end{array}$ \\
\hline [17] & $\begin{array}{l}\text { Jingtao Wang, Suk-Bong Kang, Hyoung-Wook Kim, (2004) Shear features during } \\
\text { equal channel angular pressing of a lamellae eutectic alloy. Materials Science and } \\
\text { Engineering A 383:356-361. }\end{array}$ \\
\hline$[18]$ & $\begin{array}{l}\text { Quelennec X, Menand A, Le Breton JM, Pippan R, Sauvage X, (2010) Homogeneous } \\
\text { Cu-Fe supersaturated solid solution prepared by SPD, influence of processing } \\
\text { parameters and physical mechanisms. Philos. Mag. 90:1179-1195 }\end{array}$ \\
\hline
\end{tabular}




\begin{tabular}{|c|c|}
\hline [19] & $\begin{array}{l}\text { Bachmaier A, Hohenwarter A, Pippan R (2009) New procedure to generate stable } \\
\text { nanocrystallites by severe plastic deformation.Scripta Materialia 61:1016-1019. }\end{array}$ \\
\hline [20] & $\begin{array}{l}\text { Xia K (2010) Consolidation of particles by severe plastic deformation: mechanism and } \\
\text { application in processing bulk ultrafine and nanostructured alloys and composites. Adv. } \\
\text { Eng. Mater. 12:724-729. }\end{array}$ \\
\hline$[21]$ & $\begin{array}{l}\text { Lui EW, Xu W, Wu X, Xia K (2011) Multiscale two-phase Ti-Al with high strength } \\
\text { and plasticity through consolidation of particles by severe plastic deformation. Scripta } \\
\text { Materialia } 65711-714 \text {. }\end{array}$ \\
\hline [22] & $\begin{array}{l}\text { Bachmaier A, Pippan R (2013) Generation of metallic nanocomposites by } \\
\text { severe plastic deformation. International Materials Reviews } 2013 \text { Vol 58:41-62. }\end{array}$ \\
\hline [23] & $\begin{array}{l}\text { Sauvage X, Dinda DG, Wilde G (2007) Non-equilibrium intermixing and phase } \\
\text { transformation in severely deformed Al/Ni multilayers. Scripta Mater 56:181-184. }\end{array}$ \\
\hline [24] & $\begin{array}{l}\text { Dinko Vujic, Zhixian Li, Sung H Whang (1988) Effect of Rapid Solidification and } \\
\text { Alloying Addition on Lattice Distortion and Atomic Ordering in L1o TiAI Alloys and } \\
\text { Their Ternary Alloys. Metall. Trans A, Vol 19A:2445-2455. }\end{array}$ \\
\hline [25] & $\begin{array}{l}\text { Massalski TB (1987) "Binary alloy phase diagrams", Edited by ASM, Metals Park, } \\
\text { Ohio, USA :175. }\end{array}$ \\
\hline [26] & $\begin{array}{l}\text { Ramos AS, Vieira MT (2005) Kinetics of the thin films transformation Ti/Al multilayer } \\
\gamma \text { TiAl. Surf. Coat Techno 200:326-329. }\end{array}$ \\
\hline [27] & $\begin{array}{l}\text { Gachon J-C, Rogachev AS, Grigoryan HE, Illarionova EV, Kuntz J-J, Kovalev DYu, } \\
\text { Nosyrev AN, Sachkova NV, Tsygankov PA (2005) On the mechanism of } \\
\text { heterogeneous reaction and phase formation in Ti/Al multilayer nanofilms. Acta Mater } \\
\text { 53:1225-1231. }\end{array}$ \\
\hline [28] & $\begin{array}{l}\text { Klaus-Dieter Liss, Ross E. Whitfield, Wei Xu, Thomas Buslaps, LaReine A Yeoh, } \\
\text { Xiaolin Wu, Deliang Zhang, Kenong Xia (2009) In situ synchrotron high-energy X-ray } \\
\text { diffraction analysis on phase transformations in Ti-Al alloys processed by equal- } \\
\text { channel angular pressing. J. Synchrotron Rad. } 16: 825-834 \text {. }\end{array}$ \\
\hline
\end{tabular}




\section{Figure captions}

Fig. 1 : Microstructures of the Ti-Al composite after ECAP consolidation: (a) Optical microscopy image where bright zones are $\mathrm{Al}$ rich, and (b) SEM image where dark zones are Al rich. In both cases, the contrast reveals some chemical heterogeneities at the micrometer scale.

Fig.2: Microstructures of the Ti-Al composite after ECAP consolidation: (a) STEM-HAADF, and (b) EDS map (Ti-K green, Al-K blue). Point analyses were carried out in the areas labelled 1 to 3 , providing estimates of $\mathrm{Al}$ concentrations (at.\%). Location 1: $0.6 \% \pm 0.2$, corresponding to the Ti phase; location $2: 52 \% \pm 0.5$ corresponding to the $\gamma \mathrm{TiAl}$ phase, and location 3: $7 \% \pm 0.5$ corresponding to the $\mathrm{Ti}$ phase with a significant amount of $\mathrm{Al}$ in solid solution.

Fig.3: Microstructures of the Ti-Al composite after ECAP consolidation: (a) STEM-HAADF, and (b) EDS map (Ti-K green, Al-K blue). Point analyses were carried out in the areas labelled 1 to 3, providing estimates of $\mathrm{Al}$ concentrations (at.\%). Location 1: $0.5 \% \oplus .1$, corresponding to the Ti phase; location 2: $54.0 \% \pm 0.5$ corresponding to the $\gamma \mathrm{TiAl}$ phase, and location 3: $87.5 \% \boxplus .5$ corresponding probably to the $\mathrm{Al}$ phase with $\mathrm{Ti}$ in a super saturated solid solution.

Fig.4: TEM images of the Ti-Al composite after ECAP consolidation in a region with nanoscaled grains: (a) bright field image (inset: corresponding selected area electron diffraction pattern showing the reflections typical of hcp $\mathrm{Ti}$, fcc $\mathrm{Al}, \mathrm{Al}_{3} \mathrm{Ti}, \mathrm{Al}_{2} \mathrm{Ti}$ and $\mathrm{TiAl}$ phases; (b) dark filed image obtained from the reflections circled on the SAED, showing isolated nanoscaled grains.

Fig.5: Microstructures of the Ti-Al composite after ECAP consolidation in a region with nanoscaled grains: (a) STEM-HAADF image; (b) EDS map (Ti-K green, Al-K blue). Point analyses were carried out in the areas labelled 1 and 2 , providing estimates of $\mathrm{Al}$ concentrations (at.\%). Locations 1: $64<$ at. $\% \mathrm{Al}<70$, close to the stoichiometry of the $\mathrm{Al}_{2} \mathrm{Ti}$ phase; locations 2: $84<$ at. $\% \mathrm{Al}<87$, corresponding probably to the $\mathrm{Al}$ phase with $\mathrm{Ti}$ in a super saturated solid solution.

Fig.6: Schematic representations of the different scales of the composition modulated structure resulting from the combination of BM+BP-ECAP of the Ti-Al composite. The first level of fluctuations is controlled by the co-deformation mechanism of the soft $\mathrm{Al}$ and the hard Ti phases (a). The second level is controlled by the fragmentation of the original $\mathrm{Al}$ and Ti particles resulting from plastic instabilities (b). The third level is controlled by chemical reaction at the $\mathrm{Al} / \mathrm{Ti}$ interfaces, promoted by the mechanical mixing at the atomic scale (c). 

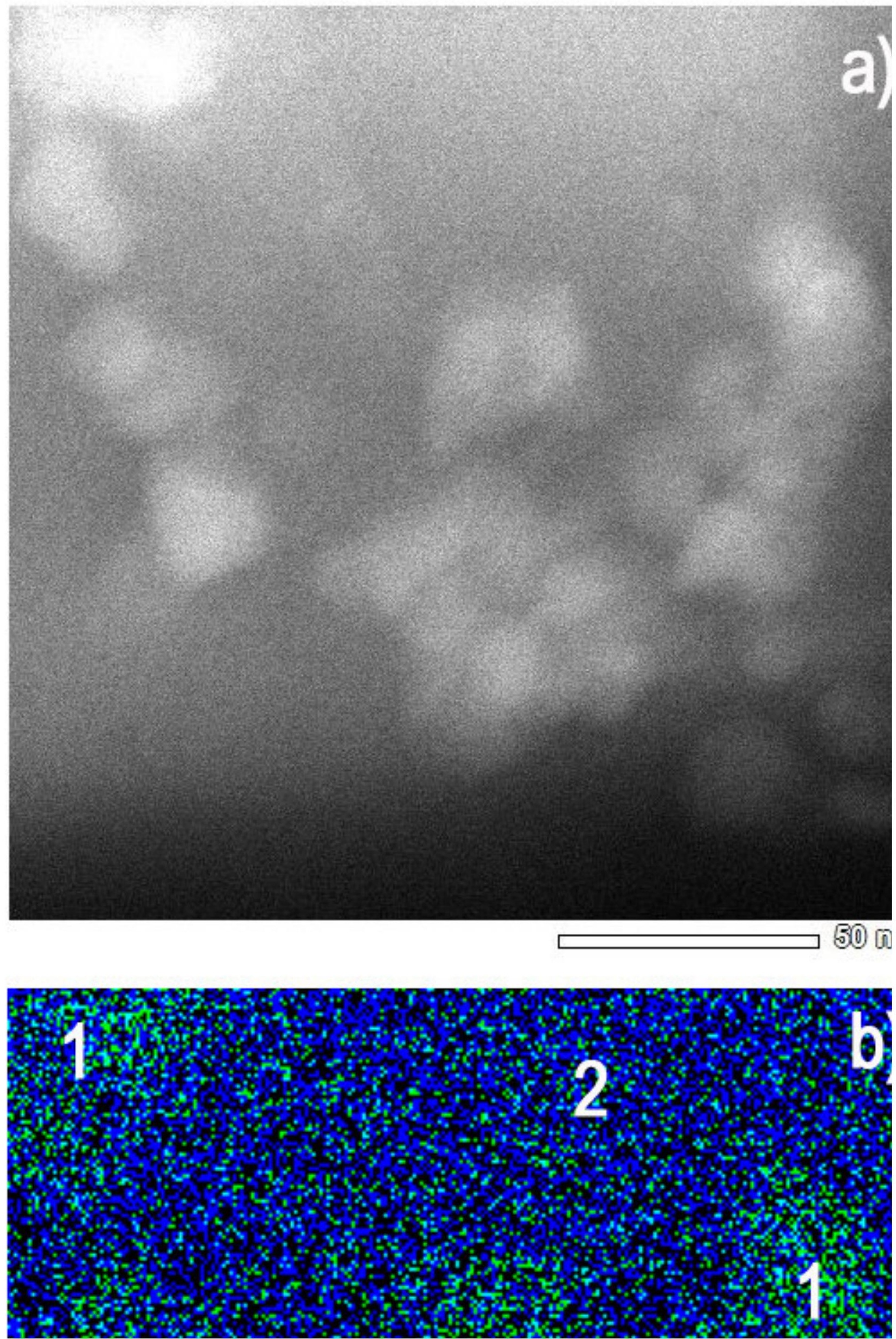


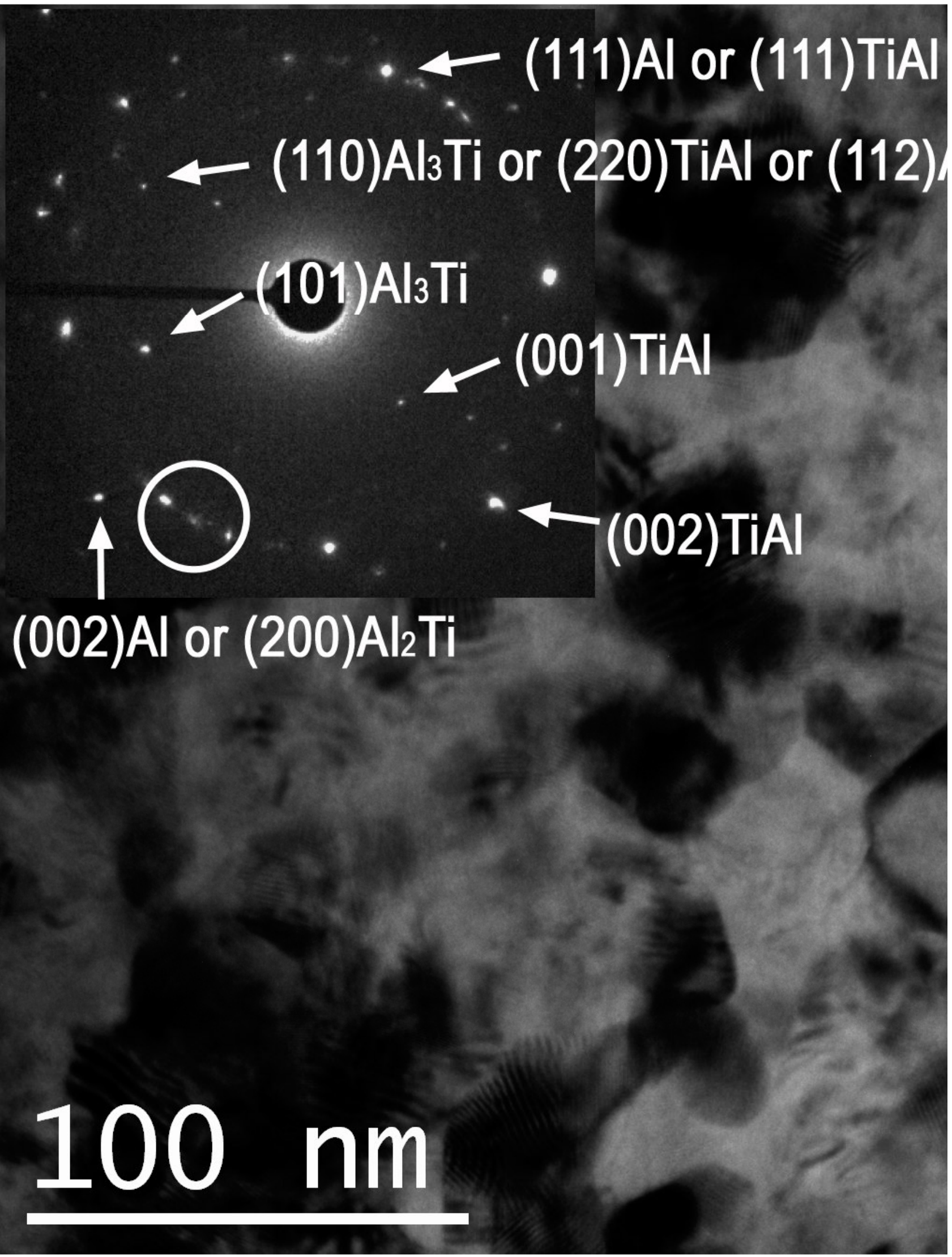



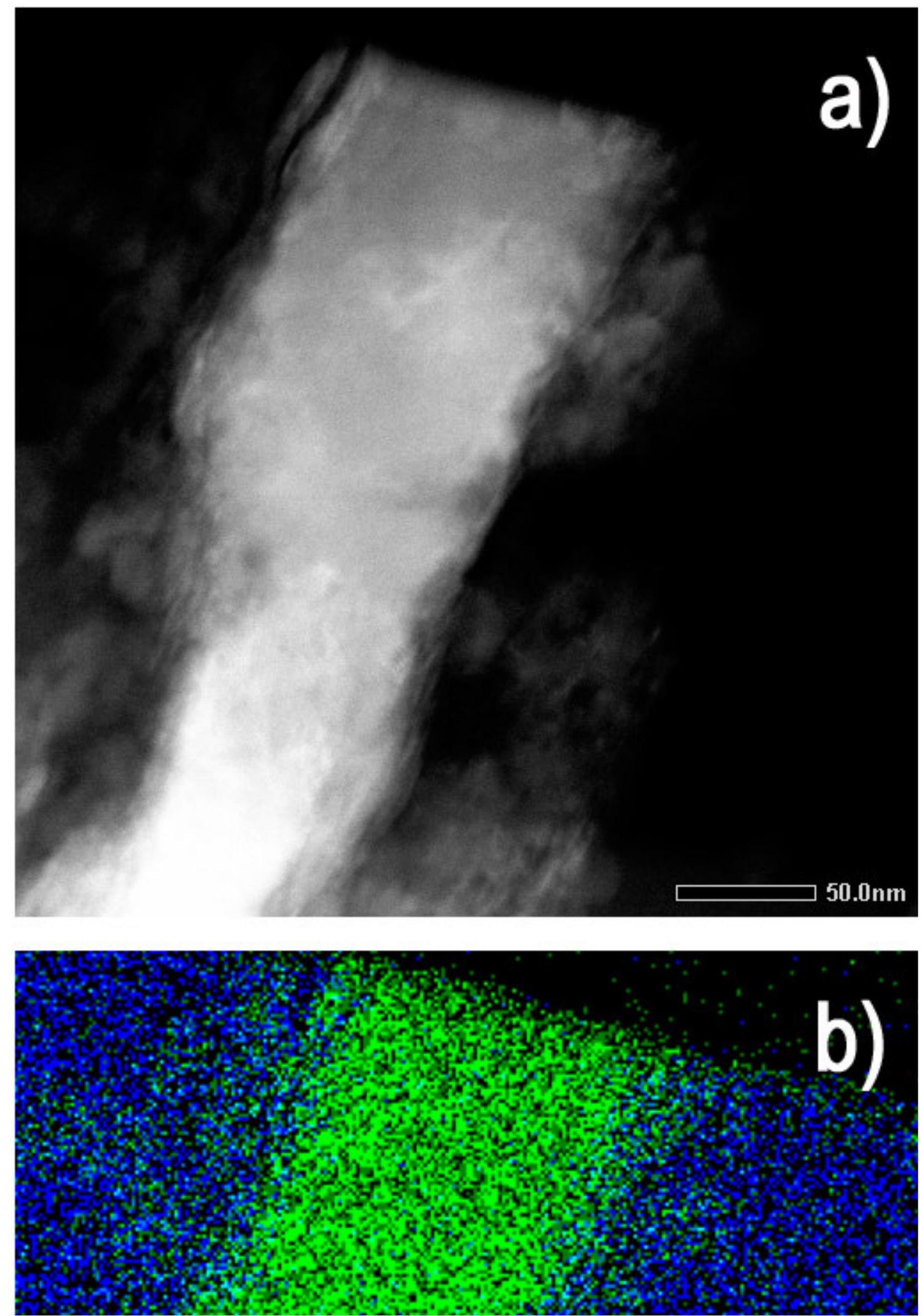

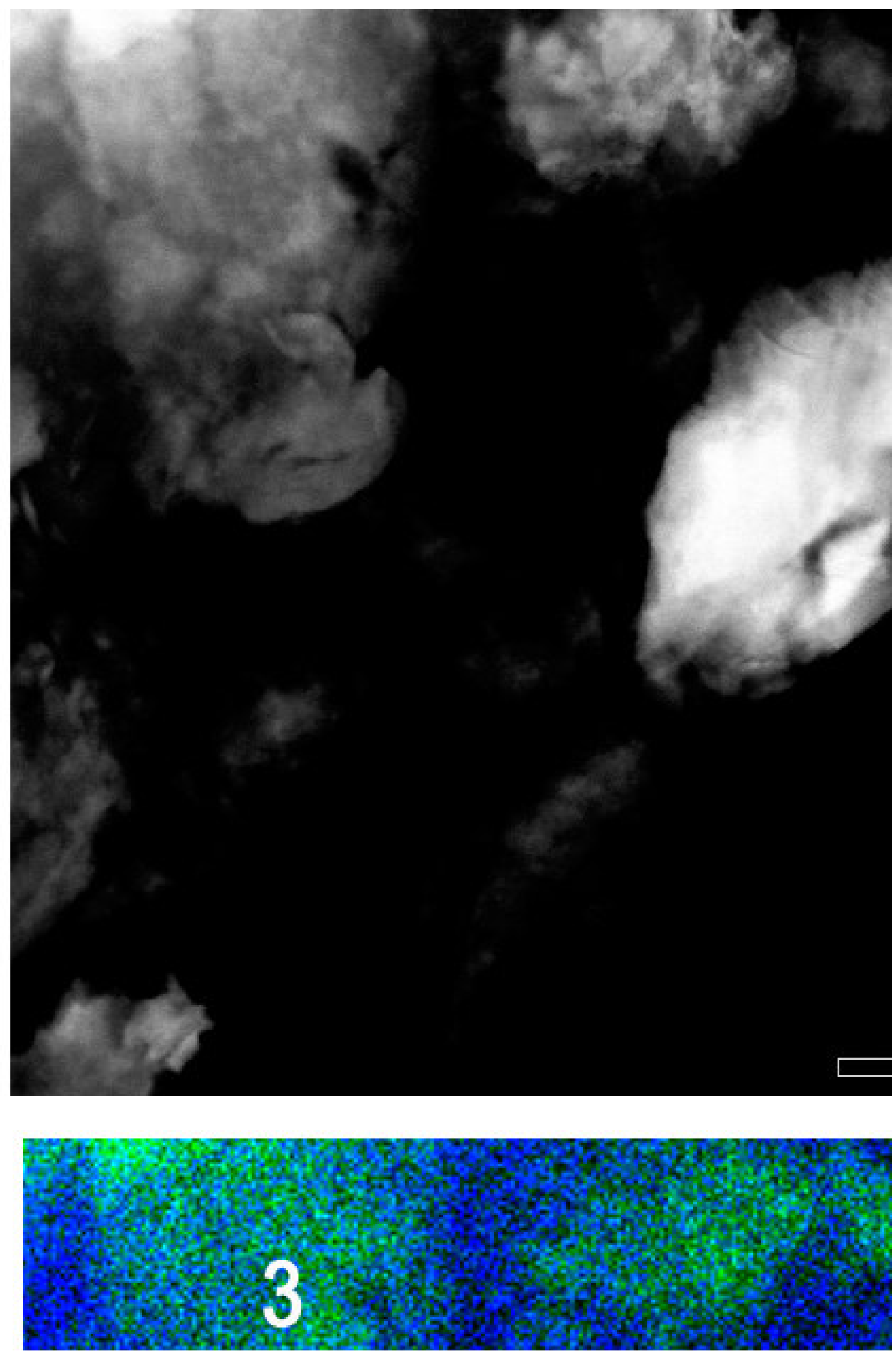

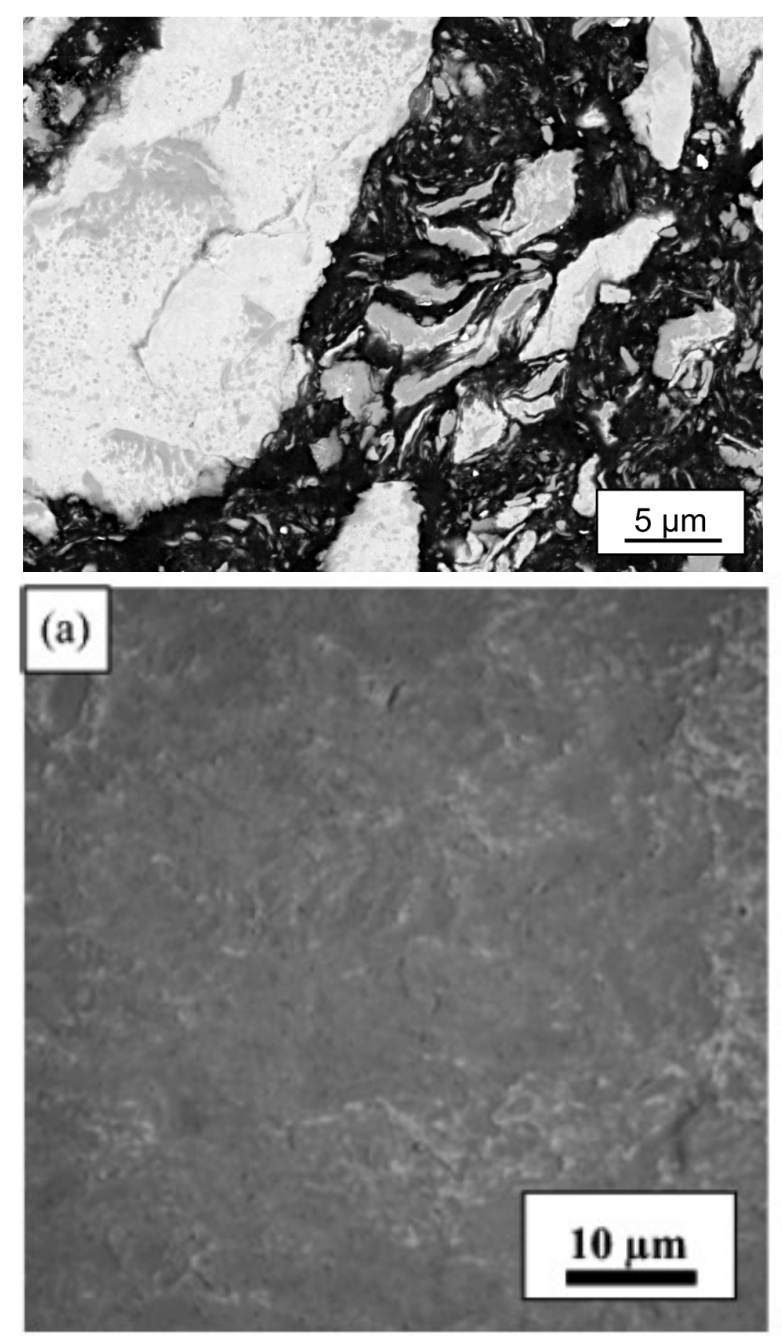


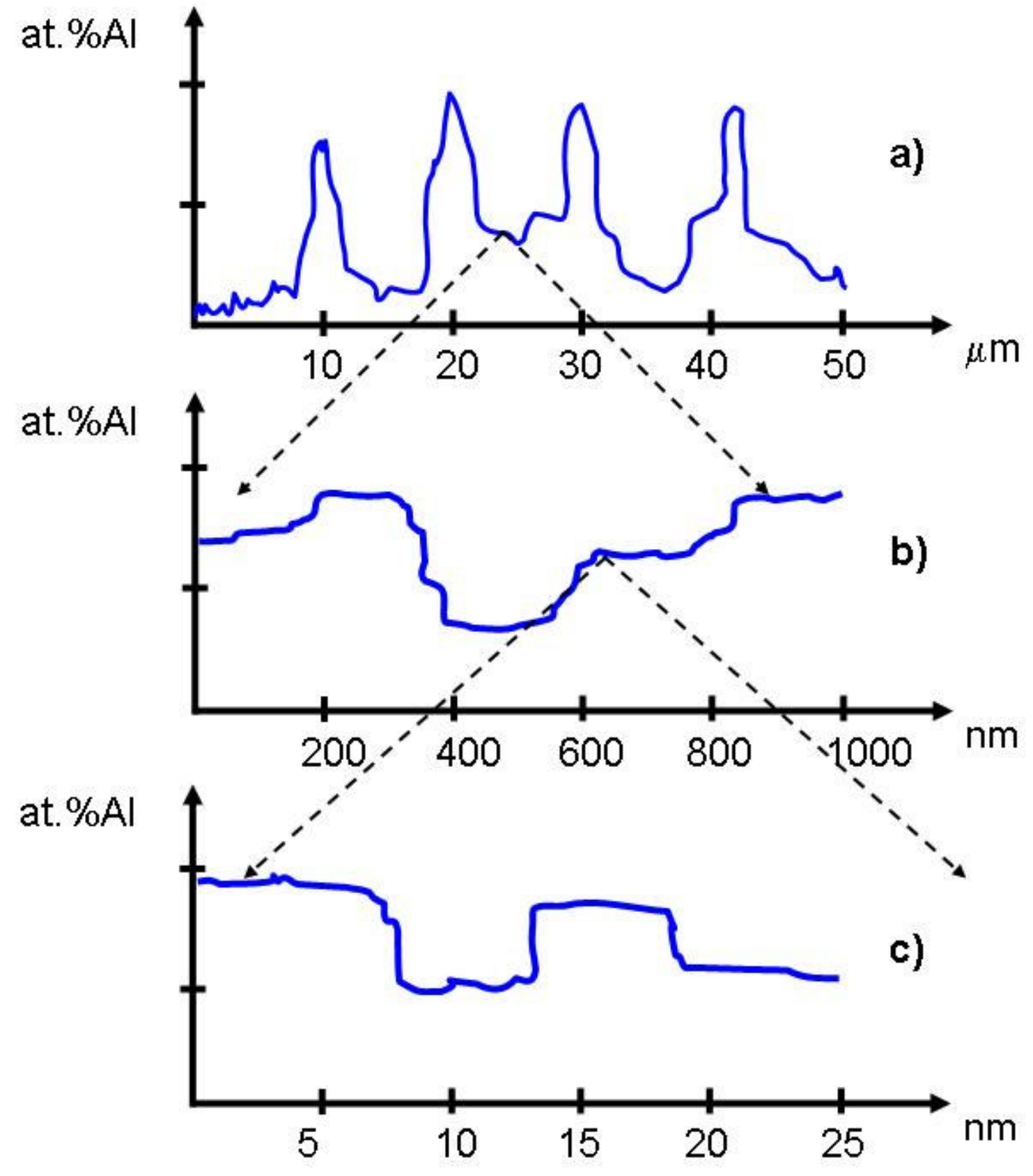




\section{University Library}

\section{- M M N E R VA A gateway to Melbourne's research publications}

Minerva Access is the Institutional Repository of The University of Melbourne

Author/s:

Sauvage, X;Lui, EW;Xia, K

Title:

Multiscale composition modulated Ti-Al composite processed by severe plastic deformation

Date:

2014-10-01

Citation:

Sauvage, X., Lui, E. W. \& Xia, K. (2014). Multiscale composition modulated Ti-Al composite processed by severe plastic deformation. JOURNAL OF MATERIALS SCIENCE, 49 (19), pp.6543-6549. https://doi.org/10.1007/s10853-014-8239-7.

Persistent Link:

http://hdl.handle.net/11343/282881 